${ }^{1}$ Klinika Chorób Wewnętrznych i Diabetologii, Uniwersytecki Szpital Kliniczny im. Wojskowej Akademii Medycznej — Centralny Szpital Weteranów, Uniwersytet Medyczny w Łodzi

${ }^{2}$ Klinika Neurologii, Uniwersytecki Szpital Kliniczny nr 1, im. N. Barlickiego, Uniwersytet Medyczny, Łódź

${ }^{3}$ Klinika Kardiologii, Uniwersytecki Szpital Kliniczny im. Wojskowej Akademii Medycznej - Centralny Szpital Weteranów, Uniwersytet Medyczny, Łódź

${ }^{4}$ Katedra Genetyki Klinicznej i Laboratoryjnej i Zakład Genetyki Klinicznej, Uniwersytecki Szpital Kliniczny im. Wojskowej Akademii Medycznej

- Centralny Szpital Weteranów, Uniwersytet Medyczny, Łódź

${ }^{5}$ Klinika Chorób Wewnętrznych i Diabetologii, Uniwersytet Warszawski

\title{
Time of onset of coronary artery disease in diabetic patients depends on genetic polymorphism in region 9p21 but not in $1 \mathrm{p} 25$
}

\section{ABSTRACT}

Introduction. Type 2 diabetes (T2DM) is an important risk factor for development of coronary artery disease (CAD) and its complications. Recent genetic studies revealed possible association between those two conditions on the genome level. In our study we analysed whether polymorphisms in loci 1q25 and 9p21, previously characterized as risk factors of CVD, have an influence on early-onset CAD in T2DM patients.

Materials and methods. Our case-control study included 338 patients suffering from T2DM and CAD. For the study purpose the cohort was divided into two groups based on the age of CAD onset: case group with earlyonset CAD ( $<55$ for males and $<65$ years for females, $n=180$ ) and control group ( $\geq 55$ and $\geq 65$ years respectively, $n=158$ ). Epidemiological data was taken from medical history and retrospective questionnaire; blood samples were collected. The rs2383206, rs1333049 and rs10911021 were genotyped using method of fluorescently labelled allele specific oligonucleotides.

Results. Statistical analysis did not reveal any significant differences between two groups in the mean duration of

Address for correspondence:

lek. Joanna Wójcik-Odyniec

Klinika Chorób Wewnętrznych i Diabetologii USK im. WAM

- Centralny Szpital Weteranów

ul. Pomorska 251, 92-213 Łódź

e-mail: wojcik.joanna1@gmail.com

Clinical Diabetology 2016, 5, 1, 7-14

DOI: $10.5603 /$ DK.2016.0002

Received: 17.11 .2015

Accepted: 04.02.2016 diabetes, metabolic parameters (weight, waist circumference, frequency of obesity according to BMI, mean blood pressure or lipids levels) and smoking history. There were statistical differences between groups in family incidence of CAD (70.0\% patients in cases vs. $45.6 \%$ in controls; $p<0.005)$, hypertension $(77.1 \%$ vs. $47.8 \%$; $p<0.005)$ and obesity $(61.2 \%$ vs. $49.0 \%$; $p<0.05)$. Genetic analysis revealed that frequency of the $G$ allele of rs2383206 in 9p21 region was significantly higher in cases than in controls $(62.4 \%$ vs $44.0 \% p<0.00001)$. Homozygotes GG were $39.4 \%$ of cases and $18.8 \%$ in controls $(p=0.0001)$. The OR for increased risk of early CAD in GG homozygotes was $2.81,95 \% \mathrm{Cl}$ : 2.39-3.24, after adjustment for conventional risk factors it was reduced to 2.58 . There was statistically significantly higher frequency of GG homozygotes among patients with poor glycaemic control $\left(\mathrm{HbA}_{1 \mathrm{c}}\right.$ $\geq 7 \% ; 41.3 \%$ vs. $15.9 ; p=0.0011$ ) and non-obese subjects (BMI <30 kg/m²; $39.7 \%$ vs. $18.2 \%, p=0.0002$ ). Similar association between genotype and risk of early CAD was found for another polymorphism rs1333049 in 9p21 region. Frequency of allele $C$ was significantly higher in cases than in controls $(56.3 \%$ vs $43.4, p=0.0036)$ and homozygotes CC were $31.6 \%$ in cases and $17.4 \%$ in controls ( $p=0.0083$ ). OR for this association was 2.2 (95\% Cl: 1.83-2.56); after adjustments 1.96. We didn't find any association between genotypes distribution of rs10911021 and early onset of CAD.

Conclusions. Our findings clearly suggest that polymorphisms in 9p21 region have an influence on development 
of early-onset CAD in T2DM, especially in non-obese patients and subjects with poor glycaemic control. (Clin Diabet 2016; 5, 1: 7-14)

Key words: T2DM, $\mathrm{HbA}_{1 \mathrm{c}^{\prime}}$ CAD, genetics, 9p21, 1q25, polimorphism

\section{Introduction}

Cardiovascular disease (CVD) is an important medical and economical problem in highly urbanized countries. According to medical statistics, coronary artery disease (CAD), stroke and other arterial thrombotic events are major reasons for disability and mortality among middle-age and elder individuals [1, 2]. Since medical consequences of stroke or myocardial infarction are often irreversible and lead to long-lasting burden for health-care system, prophylaxis and early medical intervention play a key role in management of patients with CVD. Therefore, identification of risk factors and optimal selection of therapeutic options are crucial for effective CVD prevention. Some risk factors of CVD, i.e. hypertriglyceridaemia, obesity, smoking, excessive alcohol use, are strongly related to patient's lifestyle, and are best modified by lifestyle changes. Some others like age, gender or genetic background cannot be modified, but nevertheless they are taken into account in a total CVD risk assessment in a given subject.

In the last two decades genetic studies identified number of polymorphisms and mutations contributing to the risk and outcome of cardio-vascular events. The role of some genes has been well-characterized in pathogenesis of stroke and myocardial infarction. However there are still many genome loci already defined as important for development of CVD but with unknown gene structure and function. These "hot places" were identified mainly by multiple SNP analysis (single nucleotide polymorphism) in whole genome studies searching for association between genetic variants and susceptibility to common diseases. Only for coronary artery disease more than 50 important genetic loci were found using genome-wide association studies (GWAS) [4-7]. However, so far the biological role and possible mechanism of action has been established for less than $50 \%$ of identified polymorphisms. Majority of genes important for development of CVD are associated mainly with lipids metabolism (LPA, SORT1, $\angle D L R, A P O E$ ) or blood pressure stabilization (ACE, AT1R, SH2B3) [13-15]. Other possible gene candidates, identified in multiple genome regions like 1q41, 2q36, $6 p 24,9 p 21,10 q 11.21$ or $15 q 25$ contribute probably in regulation of cell cycle, tissue growth, homeostasis, fibrinolysis and inflammatory response. Their direct mechanism of action in atherosclerosis is not clear. Further studies of molecular pathways associated with genetic predisposition to CVD may help to develop novel, effective therapies useful in prevention and treatment of vascular disorders [8-12].

Type 2 diabetes mellitus (DM) is an independent CVD risk factor. Poorly controlled diabetes leads to the development of angiopathy. Detrimental effect of DM on vasculature is additionally amplified by concomitant disorders i.e. dyslipidaemia or hypertension. In diabetes CVD develops earlier than in non-diabetes population. Moreover, CVD in diabetes may be clinically silent, thus contributing to increased mortality risk seen in this group of patients. Proper CVD risk assessment in patients with diabetes is therefore of major importance [1-3].

People with diabetes share genetic risk factors with general population, however the total effect of metabolic and hereditary mechanisms in this group can be different than in non-diabetes cohorts. The first GWA study revealed possible pathophysiological association of CVD and DM, since various polymorphisms in 9p21 region were associated both with $C A D$ and diabetes risk $[4,5]$. Results of the subsequent studies, analysing the relationship between genome and clinical features of CAD in DM were often contradictory, which was to be expected due to heterogeneity of cohorts, mixed genetic background, methodological limitations and different multivariate statistical models used $[17,18]$. Recently, new, highly specific for DM genetic CVD risk factor was identified. The polymorphism in region $1 q 25$ is associated with increased risk of CAD in diabetic patients, and not in people without diabetes. 1q25 genetic variants influence the glutamic pathway through the regulation of expression of glutamateammonia ligase, encoding by GLUL gene located in $1 q 25$ region $[19,20]$

The aim of our study was to examine the effects of two already known CVD-associated genome regions: 9p21 and 1q25 on early incidence and clinical course of $C A D$ in diabetic patients. These regions were selected because they have been previously demonstrated as important risk factors for development of premature $C A D$ in general population as well as in diabetic patients. Additionally, some previous studies suggested strong correlation of genetic-dependent CAD risk with inaccurate metabolic control of diabetes and with other metabolic abnormalities. Therefore in our analysis we have been especially focused on possible cumulative effect of poor glycaemic control and/or existence of other metabolic risk factors on final effect of genetic polymorphisms. 


\section{Material and methods}

Inclusion criteria and patient's selection

This case-control study was designed as a retrospective analysis and included 338 patients suffering from type 2 DM (T2DM) and CAD. CAD was defined as a history of acute myocardial infarction, coronary artery stent implantation or stenosis greater than $50 \%$ in one of the major coronary artery confirmed by coronarography (240 patients) or CAD diagnosis in medical records with corresponding ECG findings (98 patients). Subjects were recruited from database of the diabetes and cardiology centers of the Medical University of Lodz, (Lodz, Poland). All subjects were Polish Caucasians, inhabitants of Central Poland. Patients with type 1, type 3 and gestational diabetes, with pre-diabetes states, and patient with coronary artery disease reported but not confirmed were excluded from the study.

\section{Study procedures}

The study protocol was approved by the Ethics Committee of Medical University of Lodz and all subjects gave written consent prior to participation. Physical examination, was conducted in all patients, fasting blood samples were obtained for laboratory analysis. Data on past medical and family history, health behaviours and habits (smoking, alcohol use), use of medications, serum lipids and $\mathrm{HbA}_{1 \mathrm{c}}$ levels (measured up to 6 months prior to examination) were taken retrospectively from patients records. Characteristic of the study cohort is given in Tables 1-3.

\section{Genetic analysis}

Genomic DNA was extracted from granulocytes and lymphocytes from peripheral whole blood samples using Kit AxyPrepMiniprep (AXYGEN) according to the standard protocol.

The 9p21-rs2383206, rs1333049, 1q25-rs10911021 polymorphisms were genotyped using the TaqMan predesigned SNP genotyping assay (Applied Biosystems). According to the control of quality each 96 -cell plate has a 6 random duplicates.

\section{Statistical analysis}

The results for continuous variables were presented as arithmetical means with standard deviations ( \pm SD) or proportions. Distribution for continuous variables was calculated using Shapiro-Wilk's test to assess their normality. Statistical significance was analysed using Student's t-test (for normal distribution) or by U-Mann-Whitney test (for not-normal distribution). Categorical variables were assessed using $\chi^{2}$ test. Hardy-Wienberg's equilibrium and distribution of the genotypes between both subgroups were examined using $\chi^{2}$ test. The association between each genotype and early occurrence of CAD was examined using logistic analysis and calculated as odds ratio (OR) with 95\% confidence intervals $(\mathrm{Cl})$. We created a recessive and dominant model for not-adjusted and adjusted OR for all SNPs. Statistical analysis was done by EXCEL for Windows ver. XP. Statistical significance was set at $\mathrm{p}<0.05$.

\section{Results \\ Cohort}

338 patients with diabetes and coronary artery disease were included onto the study. Total cohort has been divided into two groups: the study group with an early diagnosis of CAD made at the age $<65$ years for

Table 1. Epidemiological and clinical characteristic of the study cohort. The study group has been defined based on "early onset" of CAD; before 65 years for females and 55 years for males. The control group includes subjects with "late onset" of CAD (CAD diagnosed at age $\geq 65$ years for females and $\geq 55$ for males)

\begin{tabular}{|c|c|c|c|}
\hline & Study group $(n=180)$ & Control group $(n=158)$ & $P$ value \\
\hline Female/male ratio (\%) & 51.1 & 31.0 & $<0.005$ \\
\hline Mean age in years $( \pm S D)$ & $68.3 \pm 9.3$ & $74 \pm 8.9$ & \\
\hline Mean age of CAD diagnosis $( \pm S D)$ & $51.2 \pm 81$ & $65.2 \pm 6.96$ & $<0.00001$ \\
\hline Incidence of MI (\%) & 74.7 & 68.4 & 0.2314 \\
\hline Mean age of first MI ( \pm SD) & $55.8 \pm 11.3$ & $65.7 \pm 8.8$ & $<0.00001$ \\
\hline Incidence of $\mathrm{AH}(\%)$ & 93.3 & 92.9 & 0.8876 \\
\hline Mean age of $\mathrm{AH}$ diagnosis ( $\pm \mathrm{SD}$ ) & $49.5 \pm 8.5$ & $56.2 \pm 9.6$ & $<0.00001$ \\
\hline Mean age of DM diagnosis ( \pm SD) & $53.9 \pm 9.5$ & $60.6 \pm 9.9$ & $<0.00001$ \\
\hline Mean duration of DM ( \pm SD) & $13.9 \pm 9.8$ & $13.2 \pm 8.9$ & 0.597 \\
\hline Stroke incidence (\%) & 19.2 & 15.2 & 0.3686 \\
\hline Smoking history ever (\%) & 69.9 & 70.8 & 0.8831 \\
\hline
\end{tabular}

$\mathrm{CAD}$ - coronary artery disease; SD — standard deviation; $\mathrm{MI}$ — myocardial infarction; $\mathrm{AH}$ — arterial hypertension; $\mathrm{DM}$ — diabetes mellitus 
Table 2. Metabolic and biochemical features of study/control group

\begin{tabular}{|c|c|c|c|}
\hline & Study group & Control group & $P$ value \\
\hline Mean weight $[\mathrm{kg} \pm \mathrm{SD}]$ & $86.8 \pm 15.1$ & $85.1 \pm 15.8$ & 0.401 \\
\hline Mean height $[\mathrm{cm} \pm \mathrm{SD}]$ & $166.6 \pm 8.7$ & $168.4 \pm 8.4$ & 0.07 \\
\hline Mean BMI $\left[\mathrm{kg} / \mathrm{m}^{2} \pm \mathrm{SD}\right]$ & $31.2 \pm 4.5$ & $29.9 \pm 4.7$ & 0.006 \\
\hline $\mathrm{BMI}<30(\%)$ & 44.8 & 55.0 & 0.0682 \\
\hline $\mathrm{BMI} \geq 30<35(\%)$ & 32.2 & 30.5 & 0.7389 \\
\hline BMI $\geq 35(\%)$ & 23.0 & 14.6 & 0.054 \\
\hline Waist $[\mathrm{cm} \pm \mathrm{SD}]$ & $108.5 \pm 10.1$ & $106.5 \pm 13.5$ & 0.201 \\
\hline Waist $\geq 80 \mathrm{~cm} \mathrm{~F}, \geq 94 \mathrm{~cm} \mathrm{M} \mathrm{( \% )}$ & 95.1 & 88.9 & 0.08 \\
\hline Total cholesterol $[\mathrm{mmol} / \mathrm{L} \pm \mathrm{SD}]$ & $4.4 \pm 1.33$ & $4.5 \pm 1.2$ & 0,395 \\
\hline LDL-cholesterol $[\mathrm{mmol} / \mathrm{L} \pm \mathrm{SD}]$ & $2.4 \pm 1.05$ & $2.4 \pm 1.07$ & 0.942 \\
\hline HDL-cholesterol $[\mathrm{mmol} / \mathrm{L} \pm \mathrm{SD}]$ & $1.3 \pm 0.56$ & $1.4 \pm 0.55$ & 0.1311 \\
\hline Triglycerides $[\mathrm{mmol} / \mathrm{L} \pm \mathrm{SD}]$ & $2.3 \pm 1.74$ & $2.0 \pm 1.25$ & 0.116 \\
\hline $\mathrm{HbA}_{1 \mathrm{c}}(\% \pm \mathrm{SD})$ & $7.9 \pm 0.17(n=113)$ & $7.8 \pm 0.19(n=98)$ & 0.595 \\
\hline
\end{tabular}

$\mathrm{BMI}$ — body mass index; SD — standard deviation; LDL — low-density lipoprotein; $\mathrm{HDL}$ — high-density lipoprotein; $\mathrm{HbA}_{1 \mathrm{c}}$ — glycated hemoglobin

Table 3. Relative risk of early CAD development associated with conventional risk factors in our study cohort

\begin{tabular}{lc}
\hline & OR \\
\hline History of smoking & 1.045 \\
Actual smoking & 0.93 \\
$\mathrm{BMI}<30$ & 0.7 \\
$\mathrm{BMI} 30-35$ & 1.08 \\
$\mathrm{BMI}>35$ & 1.75 \\
Insulin therapy & 1.24 \\
Presence of hypertension & 1.06 \\
HbA & $\geq 7 \%$ \\
$\mathrm{LDL}_{1 \mathrm{C}}$-cholesterol $>1.9 \mathrm{mmol} / \mathrm{L}$ & 1.11 \\
Sex $(\mathrm{M} / \mathrm{F})$ & 1.03 \\
\hline
\end{tabular}

$\mathrm{BMI}$ - body mass index; $\mathrm{HbA}_{1 \mathrm{c}}$ - glycated hemoglobin; $\mathrm{LDL}$ - low-density lipoprotein

females and $<55$ years for males $(n=180)$ and the control group with CAD diagnosed after 65 years for females and 55 for males $(n=158)$. As expected, mean age of CAD diagnosis was lower in the study group (51.2 \pm 8.1 yrs.) than in the controls $(65.2 \pm 6.95$ yrs.; $p<0.05)$. There were significantly more women in the study group than in the controls (51 vs. $31 \% ; p<0.05$ ). The incidence of myocardial infarction (MI) was similar in both groups $(74.7 \%$ vs. $68.4 \%, p=0.1862)$ but the mean age of first $\mathrm{Ml}$ was lower in the group with earlier CAD onset $(55.8 \pm 11.3$ vs. $65.7 \pm 8.8, p=0.00001)$. However, we found that MI was more often the first clinical symptom of heart disease in the control group than in the study group. Hypertension was universally present in both groups (93.3\% vs. 92.9\%), however age at which it was diagnosed was lower in the study group $(49.6 \pm 8.5$ vs. $56 \pm 9.8, \mathrm{p}<0.00001)$. Subjects in the study group have been also statistically earlier diagnosed with diabetes $(53.9 \pm 9.5$ vs. $60.6 \pm 9.93$ yrs.; $p<0.00001$ ) compared with the control group, however mean diabetes duration, treatment and numbers of insulin injections were comparable between both groups. There was also no difference in history of smoking (69.9\% vs. $70.8 \%)$ and stroke incidence $(19.2 \%$ vs. $15.5 \% ; p=0.36)$. Mean body weight, and waist circumference were almost the same in both groups. Slight but statistically significant difference in BMI was found $(31.2 \pm 4.5$ in the study group vs. $29.9 \pm 4.7 \mathrm{~cm}$ in the control group; $p=0.006$ ), however there was no statistical difference in the prevalence of obesity (BMI > 30) between both groups (32.2 vs. 30.5\%, $p$ value $\leq 0.7389$ ). There were also no significant differences in blood lipid nor $\mathrm{HbA}_{1 \mathrm{c}}$ levels. Odds ratio (OR) of early CAD development calculated for the single risk factor is shown in Table 3. Incidence of family history of CAD $(70.0 \%$ in the study group vs $45.6 \%$; in the control group; $p<0.00001)$, obesity $(61.2 \%$ vs. $49.0 \%$; $p<0.0297)$, diabetes ( $51.5 \%$ vs. $28.4 \%, p<0.0023$ ) and hypertension (77.1\% vs. $47.8 \% ; p<0.00001)$ were statistically different in both groups what is presented in Table 4.

\section{Analysis of polymorphisms in 9p21}

and 1q24 regions

In our study cohort Allele frequencies of CAD-associated SNPs in 9p21 region (rs2383206 and rs1333049) and $1 q 25$ region (rs10911021) were found to be in Hardy-Weinberg equilibrium.

For both SNP's in 9p21region, there were significant differences in allele and genotype frequencies 
Table 4. Role of hereditary predisposition to CAD and CAD-related diseases in early development of CAD in diabetic patients. Family history is considered as positive if disease appeared in subject's $1^{\text {st }}$ degree relatives

\begin{tabular}{lccc}
\hline & $\begin{array}{c}\text { Study } \\
\text { group }\end{array}$ & $\begin{array}{c}\text { Control } \\
\text { group }\end{array}$ & P value \\
& 70.0 & 45.6 & $<0.00001$ \\
Family history of CAD (\%) & 61.2 & 49.0 & 0.0297 \\
Family history of obesity (\%) & 51.5 & 28.4 & 0.0023 \\
Family history of DM (\%) & 77.1 & 47.8 & $<0.00001$ \\
Family history & & & \\
of hypertension (\%) & & & \\
\hline
\end{tabular}

CAD - coronary artery disease; DM — diabetes mellitus

between the study and control group. For rs2383206 locus (Table 5), previously determined risk allele $\mathrm{G}$ was present in $62.4 \%$ of subjects with an early onset of CAD, comparing to $44 \%$ in the control group ( $p<0.00001$ ). $\mathrm{G} / \mathrm{G}$ genotype associated with risk of CAD was present in $39.4 \%$ in study group comparing to $18.8 \%$ in the control one $(p=0.0001)$. For study purpose, based on previous publications, we used a recessive model of analysis for the SNP (GG vs. AA + AG), and such a difference in genotype frequencies between groups was equivalent with increased risk of early CAD in GG homozygotes (OR 2.81, 95\% Cl: 2.39-3.24). In multivariant multivariate analysis of our data, after statistical adjustment for all conventional risk factors of CVD (gender, obesity, smoking and hypertension history, lipid levels, glycaemic control) only slightly reduced OR for SNP rs2383206 (from 2.81 to 2.58).
For another SNP from 9p21 region, rs1333049, similar difference in allele frequency was found (Table 6), although the analysis was done in a smaller number of subjects $(n=276)$. Allele $C$, previously demonstrated as associated with CAD risk, was more frequent in study group comparing to the control one $(56.3 \%$ vs. $43.4 \%, p=0.0036)$. CC homozygote frequency under recessive model among the patient with early CAD was $31.6 \%$ and $17.4 \%$ in control individuals ( $p=0.0083$ ). In logistic regression analysis the risk for early onset of CAD for subjects with CC genotype was significantly higher (OR 2.2, 95\% Cl: 1.83-2.91, adjusted OR 1.96).

The genetic analysis of polymorphism in $1 \mathrm{q} 25$ locus: rs10911021 (related to glutamic pathway) did not reveal any significant difference in the alleles and genotypes frequencies between the control and study group in our cohort (data not published).

\section{Relationship of 9p21 genotype}

and clinical phenotype

Poor glycaemic control strongly altered the 9p21-related risk of early CAD in diabetic patients (Figure 1). The percentage of patients with $\mathrm{HbA}_{1 \mathrm{c}}>7 \%$ and risk genotype $\mathrm{G} / \mathrm{G}$ is $41.3 \%$ in patients with early CAD and only $15.9 \%$ in the control group $(p=0.0011)$. However, there was no statistical difference between the GG frequency in the control and study group among patients with low $\mathrm{HbA}_{1 \mathrm{c}}<7 \%$ (31.6\% vs. 22.9, $\mathrm{p}=0.4039$ ). OR for early CAD risk in GG homozygotes with $\mathrm{HbA}_{1 \mathrm{c}}>7 \%$ was 3.73, whereas total OR (evaluated independently of $\mathrm{HbA}_{1 \mathrm{c}}$ levels) was 2.81 (Table 6). Among the subjects with $\mathrm{HbA}_{1 \mathrm{c}}<7 \%$ - OR for early CAD associated with risk

Table 5. The genotype distribution and alleles frequencies for rs2383206 with evaluated OR for development of early CAD among carriers of the risk allele. OR for recessive model (GG vs. AA + AG)

\begin{tabular}{lcccccc}
\hline rs2383206 & $\begin{array}{c}\text { Study group }(n=170) \\
(\%)\end{array}$ & $\begin{array}{c}\text { Control group }(\mathbf{n}=149) \\
(\%)\end{array}$ & P value & OR & $95 \% \mathrm{Cl}$ & OR adjusted* \\
\hline $\mathrm{A} / \mathrm{A}$ & $14.7 \%$ & $30.9 \%$ & 0.0005 & 0.4 & & \\
$\mathrm{~A} / \mathrm{G}$ & $45.9 \%$ & $50.3 \%$ & 0.4270 & 0.8 & & 2.57 \\
$\mathrm{G} / \mathrm{G}$ & $39.4 \%$ & $18.8 \%$ & 0.0001 & 2.8 & $2.39-3.24$ & 24 \\
\hline
\end{tabular}

*Adjusted by: sex (F/M),HA (Y/N), total chol < 4.5, LDL-chol > 1.9, HDL-chol $<1.0, \mathrm{TGL} \geq 1.7, \mathrm{BMI} \geq 35 /<35$, smoking now $(\mathrm{Y} / \mathrm{N}), \mathrm{HBA}{ }_{1 \mathrm{c}}(\geq 7 \%)$

Table 6. The genotype distribution and alleles frequencies for rs1333049 with evaluated OR for development of early CAD among carriers of the risk allele. OR for recessive model (CC vs. GG + CG)

\begin{tabular}{|c|c|c|c|c|c|c|}
\hline rs1333049 & $\begin{array}{c}\text { Study group }(n=136) \\
(\%)\end{array}$ & $\begin{array}{c}\text { Control group }(n=121) \\
(\%)\end{array}$ & $P$ value & OR & $95 \% \mathrm{Cl}$ & OR adjusted* \\
\hline $\mathrm{G} / \mathrm{G}$ & $19.1 \%$ & $30.6 \%$ & & 0.54 & & \\
\hline$C / G$ & $49.3 \%$ & $52.1 \%$ & & 0.89 & & \\
\hline $\mathrm{C} / \mathrm{C}$ & $31.6 \%$ & $17.4 \%$ & 0.0083 & 2.2 & $1.83-2.58$ & 1.97 \\
\hline
\end{tabular}

*Adjusted by: sex (F/M), HA (Y/N), total chol < 4.5, LDL-chol $>1.9, \mathrm{HDL}$-chol $<1.0, \mathrm{TGL} \geq 1.7, \mathrm{BMI} \geq 35 /<35$, smoking now $(\mathrm{Y} / \mathrm{N}), \mathrm{HBA}{ }_{1 \mathrm{c}}(\geq 7 \%)$ 


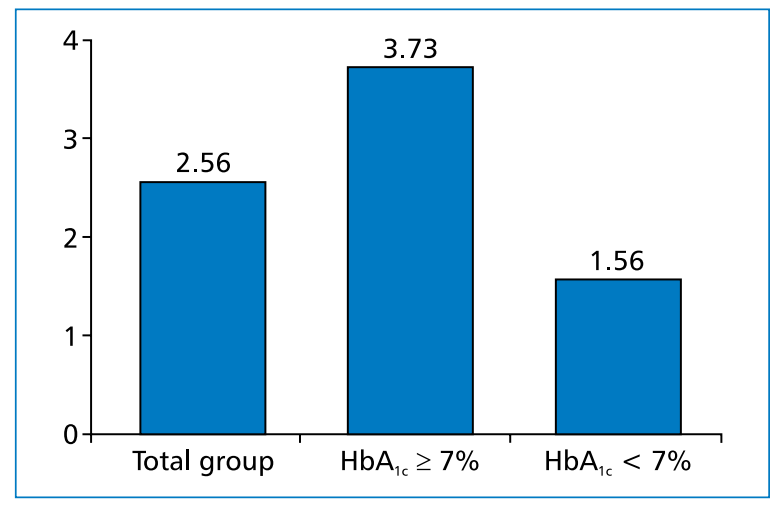

Figure 1. The risk of development early CAD in GG carriers rs23803206 with association of poor glycaemic control $\left(\mathrm{HbA}_{1 \mathrm{c}} \geq 7 \%\right)$

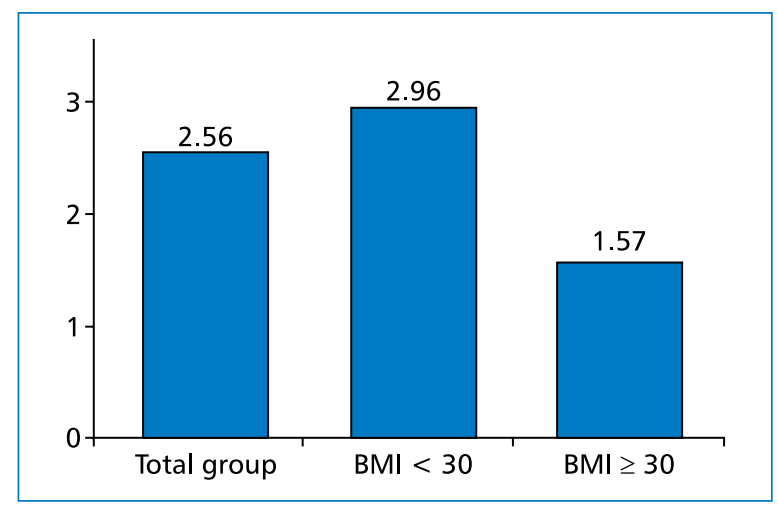

Figure 2. The risk of development early CAD in GG carriers $\mathrm{rs} 23803206$ with association of $\mathrm{BMI}<30 \mathrm{~kg} / \mathrm{m}^{2}$ and $\geq 30 \mathrm{~kg} / \mathrm{m}^{2}$ )

genotype was reduced to 1.56 . Moreover, although the $\mathrm{G} / \mathrm{G}$ phenotype was still more frequent in patients with early CAD and good glycaemic control (31.6\%) comparing to subjects with late $C A D$ and good glycaemic control $\left(\mathrm{HbA}_{1 \mathrm{c}}<7 \%\right)(22.9 \%)$, this difference did not achieve the statistical significance $(p=0.403)$. Interestingly, the patients with $\mathrm{BMI} \geq 30$ and genotype $\mathrm{G} / \mathrm{G}$ in locus rs2383206 had relatively lower risk of development of early CAD (OR 1.57) in logistic regression analysis than non-obese subjects (OR 2.96) (Figure 2).

\section{Discussion}

The role of genetic polymorphisms in pathogenesis of CVD is highlighted since the results of first GWAS were published $[4,5]$. In this study we have focused on 3 previously described regions of human genome associated with increased risk of CAD in general and diabetic population: $9 p 21$ and $1 q 25[16,19,21,22]$ searching for the correlation of those polymorphisms with early onset of coronary disease in diabetic patients.
The role of $9 p 21$ region in the pathogenesis of CVD was established in $2007[4,5]$ and confirmed in high number of genetic studies both in general and clinically-selected populations (e.g. in DM or rheumatoid arthritis) [6, 7, 23]. In present study we demonstrated that two previously known polymorphisms in 9p21 region (rs2383206 and rs1333049) are important for development of early ischaemic heart disease in younger patient with DM. Carriers of risk alleles for both SNPs have consistently higher risk of early CAD, estimated in logistic regression analysis. OR over 2.5 associated with rs 2383206 locus and 2.0 for rs 1333049 , after adjustment for all known classic risk factors in logistic regression model, suggest a strong correlation of 9p21 loci with early CAD onset. Our observations confirm the data previously published by Doria et al. on the role of 9p21 SNPs in CAD development in DM [24]. It is also consistent with previous publications on the role of 9 p21 region in progression of lesions in the coronary arteries, since the patients with risk alleles develop symptoms of CAD earlier than non-carriers $[25,26]$. There are contradictory reports about the increased risk of $\mathrm{Ml}$ among $9 \mathrm{p} 21$ carriers - some authors like Zhang [27] Saleheen [28], Abdullah [25] have found an association with premature MI. In our study we didn't see a significantly higher incidence of $\mathrm{MI}$ among patients with early CAD incidence. This observation is consistent with other author's findings $[29,30,32,33]$, that didn't find connection with early $\mathrm{MI}$ and 9p21 polymorphisms. Differences in the correlation between the risk genotype and $\mathrm{MI}$ incidence found in the particular studies might suggest, that two separated haploblocks co-exist in 9p21 region: "proatherogenic one" (including rs2383206, rs1333049) connected with CAD occurrence and another "prothrombotic" - associated with MI risk [37]. Nonetheless, possible correlation between genotype and MI incidence could have potential influence on results of our retrospective study by "survival effect", since MI is the most serious consequence of $C A D$, associated with high mortality. In our study mean age of a first MI was lower in early group, and the difference reached statistical significance $(55.8 \pm 11.3$ vs. $65.7 \pm 8.8$, $\mathrm{p}<0.0001$ ); however, the incidence between both groups was comparable. Potential mortality of $\mathrm{MI}$ is associated with many additional factors, like patient's general condition or age, but also with extensity of MI. In our opinion, younger patients with more rapid progression of atherosclerotic plaque (due to genetic predisposition) and with potentially lower chance for developing efficient collateral circulation, could have higher risk of sudden death during the first episode of MI. So, "survival effect" is rather not expected between 
the carriers of risk alleles, but, further prospective studies should be conducted to confirm our hypothesis.

Precise mechanisms of action of 9p21 region SNPs in CAD is not clear, since a major risk allele in this region is located in anti-sense non-coding RNA INK4 locus (called ANRIL) [34]. This genome area could potentially have regulatory function on expression of cyclin-dependent kinase inhibitors encoded by CDKN2A and $C D K N 2 B$ genes and controlling the cell cycle and cellular proliferation [35]. The inhibitory effect of 9p21 on kinase inhibitors coded on chromosome 9 may be also indirectly associated with interferon-gamma/ /STAT1 pathway (since the risk allele in 9p21 region is in linkage disequilibrium with two SNPs existing in binding site for transcription factor STAT1). Nevertheless, 9p21-associated susceptibility to CVD is independent of other risk factors, like hypertension or cholesterol level. Therefore, the 9p21 region seems to be a good candidate for a novel therapeutic option in coronary artery disease or stroke, especially regarding high incidence of risk allele in Caucasian ( $75 \%$ ) and Asian population [36]. OR for GG homozygotes (rs2383206) is the highest among all analysed risk factors (Table 3). Also statistical adjustment by known risk factors in logistic regression model does not change OR evaluated for particular SNPs from 9p21 region, what suggest independent, unique mechanism of 9 p21 loci in expression of premature CAD.

Still, we have also identified some metabolic conditions that can affect the 9p21-associated risk of early CAD. Disadvantageous biological effect of rs2383206 on the onset of CAD can be strongly upregulated in patients with poor glycaemic control (Figure 1). These findings are parallel with previous observations of Doria et al. on the role of genetic and metabolic conditions in pathogenesis of CAD during DM [24]. Additionally, we have found that negative effect of 9p21 polymorphism on early onset of CAD in diabetic patients is particularly pronounced in the patients without obesity (BMI $<30 \mathrm{~kg} / \mathrm{m}^{2}$ ). Since obesity is the risk factor of both $D M$ and CAD (also in our cohort OR 1.57), it is striking that patients with optimal or sub-optimal weight control may be more susceptible to early CAD (Figure 2). It demonstrates that obesity and 9p21-mediated predisposition of CAD are independent risk factors for atherosclerosis in coronary arteries and suggests that the disadvantage of carriage of both risk alleles in 9p21 locus is more obvious in non-obese patients. Moreover, it may suggests that genetic risk factors are more important than metabolic ones and they should be taken under consideration as a part of a risk score scales.

Besides of 9p21 region, we have also analysed other polymorphism on chromosome 1 associated with
CAD risk - rs10911021 [19, 37]. We have not found any association of polymorphism in locus rs10911021 in 1 q25 region with risk of premature CAD. Activity of GLUL gene (regulator of expression of glutamateammonia ligase) located in 1q25 region is particularly and selectively related to risk of CAD in DM $[19,20]$. So, rs10911021 seemed to be a good candidate for our study. However, we were unable to find any difference in allele and genotype frequencies between study and control groups. It could be simply explained by the fact that all patients contributing to our study have DM and 1q25-mediated predisposition to CAD may depend on polymorphism in this region in binary way. So, the phenotype associated with SNP rs10911021 might determine incidence of CAD but not the time of its onset.

The strength of the study is the stringent criteria used for the sample selection for the study - polish diabetic population with CAD and the $p$ value for the association. Genotyping method with TaqMan predesigned primers is reliable, and duplicates confirmed accuracy of results. However, our study has clear limitations, like the relative small sample size (that enables an identification of more specific sub-groups and further genetic analysis of identified cohorts) or difference in sex distribution (that in our opinion may be ignored, since the criteria of recruitment to clinical groups are different for both genders). Also retrospective character of our study, must be provided for analysis of our findings. As we mentioned, the "survival effect" is rather not expected in context of obtained results. However other limitations specific for retrospective studies, like continuous changes of medical standards for diagnosis and management of both diseases as well as improving outcome after early treatment of DM and CAD during last decade, may potentially affect the results and should be considered during interpretation of data.

In summary, we confirmed a role of 9p21 region as an important risk factor of CAD in diabetic patients. A strong association of SNPs frequencies (GG for rs2383206 and CC for rs1333049) with risk of early CAD onset was found. Genetic predisposition associated with 9p21 region is independent of any other known risk factor evaluated in our patients. Moreover, the effect of 9p21 is amplified by poor glycaemic control $\left(\mathrm{HbA}_{1 \mathrm{c}}>7 \%\right)$ and seems to be especially prominent in patients with relatively normal or only slightly elevated BMI $\left(<30 \mathrm{~kg} / \mathrm{m}^{2}\right)$. All in all, since polymorphisms are stable/constant during lifetime, genotyping them could distinguish a group of patients who are especially recommended for preventive treatment and modification of lifestyle. Since hereditary susceptibility to CVD is known already for a while, adding even the single, 
well-characterized polymorphism to CAD-risk scale can significantly improve its power and accuracy.

The authors would like to thank Mr. Daniel Wójcik for help in statistical analysis of data.

This work was supported by Grant of Polish Diabetes Association to Young Researcher founded to Joanna Wójcik-Odyniec on May, 2011

\section{REFERENCES}

1. Sieradzki J. Cukrzyca. Tom 1. Via Medica, Gdańsk 2015.

2. Joslin's Diabetes Mellitus. Khan R (ed). Lippincott Williams \& Wilkins, Boston 2005.

3. Szczeklik A. Choroby wewnętrzne. Medycyna Praktyczna, Kraków 2014.

4. McPherson R, Pertsemlidis A, Kavaslar N et al. A common allele on chromosome 9 associated with coronary heart disease. Science 2007; 316: 1488-1491.

5. Helgadottir A, Thorleifsson G, Manolescu A et al. A common variant on chromosome 9p21 affects the risk of myocardial infarction. Science 2007; 316: 1491-1493.

6. Samani NJ, Erdmann J, Hall AS et al.; WTCCC and the Cardiogenics Consortium., Genomewide association analysis of coronary artery disease. N Engl J Med. 2007; 357: 443-453.

7. Wellcome Trust Case Control Consortium Genome-wide association study of 14,000 cases of seven common diseases and 3,000 shared controls. Nature 2007; 447: 661-678.

8. Samani NJ1, Braund PS, Erdmann J et al. The novel genetic variant predisposing to coronary artery disease in the region of the PSRC1 and CELSR2 genes on chromosome 1 associates with serum cholesterol. J Mol Med (Berl) 2008; 86: 1233-1241.

9. Qi L, Ma J, Qi Q, Hartiala J, Allayee H, Campos H. Genetic risk score and risk of myocardial infarction in Hispanics. Circulation 2011; 123: 374-380.

10. Roberts R, Stewart AF. Genes and coronary artery disease: where are we? J Am Coll Cardiol 2012; 60: 1715-1721.

11. Doria A, Abumrad NA. Genome-wide associations and metabolic disease: the big revolution. Curr Opin Clin Nutr Metab Care 2008; 11: 363-365.

12. Dandona $\mathrm{S}$, Roberts $\mathrm{R}$. The role of genetic risk factors in coronary artery disease. Curr Cardiol Rep 2014; 16: 479

13. Dauriz M, Meigs JB. Current insights into the joint basis of type 2 diabetes and coronary heart disease. Curr Cardiovasc Risk Rep 2014; 8: 368-388.

14. Munir MS, Wang Z, Alahdab F et al. The association of 9p21-3 locus with coronary atherosclerosis: a systematic review and meta-analysis. BMC Med Genet 2014; 15: 66.

15. Yamada Y, Ichihara S, Nishida T. Molecular genetics of myocardial infarction. Genomic Med 2008; 2: 7-22.

16. Silander K, Tang H, Myles S et al. Worldwide patterns of haplotype diversity at $9 \mathrm{p} 21.3$, a locus associated with type 2 diabetes and coronary heart disease. Genome Med 2009; 1: 51.

17. Koch W, Türk S, Erl A et al. The chromosome 9 p21 region and myocardial infarction in a European population. Atherosclerosis 2011; 217: 220-226.

18. Bhanushali AA, Parmar N, Contractor A, Shah VT, Das BR. Variant on 9p21 is strongly associated with coronary artery disease but lacks association with myocardial infarction and disease severity in a population in Western India. Arch Med Res 2011; 42: 469-474.
19. Qi L, Qi Q, Prudente S et al. Association between a genetic variant related to glutamic acid metabolism and coronary heart disease in individuals with type 2 diabetes. JAMA 2013; 310: 821-828.

20. van der Vos KE, Coffer PJ. Glutamine metabolism links growth factor signaling to the regulation of autophagy. Autophagy 2012; 8: 1862-1864.

21. Willer CJ, Sanna S, Jackson AU et al. Newly identified loci that influence lipid concentrations and risk of coronary artery disease. Nat Genet 2008; 40: 161-169.

22. Ye S, Willeit J, Kronenberg $\mathrm{F}$ et al. Association of genetic variation on chromosome 9p21 with susceptibility and progression of atherosclerosis: a population-based, prospective study. J Am Coll Cardiol 2008; 52: 378-384

23. Helgadottir A, Thorleifsson G, Magnusson KP et al. The same sequence variant on 9p21 associates with myocardial infarction, abdominal aortic aneurysm and intracranial aneurysm. Nat Genet 2008; 40: 217-224.

24. Doria A, Wojcik J, Xu R et al. Interaction between poor glycemic control and 9p21 locus on risk of coronary artery disease in type 2 diabetes. JAMA 2008; 300: 2389-2397.

25. Abdullah KG, Li L, Shen GQ et al. Four SNPS on chromosome 9p21 confer risk to premature, familial CAD and MI in an American Caucasian population (GeneQuest). Ann Hum Genet 2008; 72: 654-657.

26. Samani NJ, Raitakari OT, Sipilä K et al. Coronary artery diseaseassociated locus on chromosome 9p21 and early markers of atherosclerosis. Arterioscler Thromb Vasc Biol 2008; 28: 1679-1683.

27. Zhang Q, Wang XF, Cheng SS et al. Three SNPs on chromosome 9p21 confer increased risk of myocardial infarction in Chinese subjects. Atherosclerosis 2009; 207: 26-28.

28. Saleheen D, Alexander M, Rasheed A et al. Association of the 9p21.3 locus with risk of first-ever myocardial infarction in Pakistanis: Case-control study in South Asia and updated meta-analysis of Europeans. Arterioscler Thromb Vasc Biol 2010; 30: 1467-1473.

29. Bhanushali AA, Parmar N, Contractor A, Shah VT, Das BR. Variant on 9 p21 is strongly associated with coronary artery disease but lacks association with myocardial infarction and disease severity in a population in Western India. Arch Med Res 2011; 42: 469-474.

30. Maksimov VN, Kulikov IV, Orlov PS et al. Evaluation of association between 9 genetic polymorphism and myocardial infarction in the Siberian population. Vestn Ross Akad Med Nauk 2012; 5: 24-29.

31. Shen GQ, Rao S, Martinelli N et al. Association between four SNPs on chromosome 9p21 and myocardial infarction is replicated in an Italian population. J Hum Genet 2008; 53: 144-150.

32. Dehghan A, van Hoek M, Sijbrands EJ et al. Lack of association of two common polymorphisms on 9p21 with risk of coronary heart disease and myocardial infarction; Results from a prospective cohort study. BMC Med 2008; 6: 30.

33. Holdt LM, Beutner F, Scholz $\mathrm{M}$ et al. ANRIL expression is associated with atherosclerosis risk at chromosome 9p21. Arterioscler Thromb Vasc Biol 2010; 30: 620-627.

34. Holdt LM, Sass K, Gäbel G, Bergert H, Thiery J, Teupser D. Expression of Chr9p21 genes CDKN2B (p15(INK4b)), CDKN2A (p16(INK4a), p14(ARF)) and MTAP in human atherosclerotic plaque. Atherosclerosis 2011; 214: 264-270.

35. Roberts R, Stewart AF. 9p21 and the genetic revolution for coronary artery disease. Clin Chem 2012; 58: 104-112.

36. Hauser ER, Crossman DC, Granger CB et al. A genomewide scan for early-onset coronary artery disease in 438 families: the GENECARD Study. Am J Hum Genet 2004; 75: 436-447.

37. Fan M, Dandona S, McPherson R et al. Two chromosome 9p21 haplotype blocks distinguish between coronary artery disease and myocardial infarction risk. Circ Cardiovasc Genet 2013; 6: 372-380. 